\title{
Freedom to achieve: addressing the attainment gap through student and staff co-creation
}

\author{
Lucy Ansley, Richard Hall \\ De Montford University
}

\begin{abstract}
Understanding and enhancing the experience of individuals and communities who have experienced marginalising structures and cultures have become an important area of research across higher education. This work forms an attempt to address injustice through a critical focus on inclusion and ideas of diversity. However, it also enables a reappraisal of ideas of student-staff partnership and co-creation, and student-as-producer. Building upon Kingston University's value-added metric and Inclusive Curriculum Framework, De Montfort University has developed its own approach to engaging with differential attainment gaps, in part by embedding co-creation at the heart of its 'Freedom to Achieve' project. Co-creation enhances the University's understanding of the experiences of Black, Asian and Minority Ethnic (BAME) students and supports all students to become agents for change. Between January and April 2018, as a pilot for later project-wide implementation, the Freedom to Achieve team facilitated a series of co-creation events at both institution and programme level. This paper presents an evaluation of the co-creation approach alongside initial findings from the events and explains how these will inform the continuing development of the Freedom the Achieve project.
\end{abstract}

\section{Introduction}

The Freedom to Achieve (FTA) Project at De Montfort University (DMU) is an institutional response to the difference in attainment between Black, Asian and Minority Ethnic (BAME) students and their white counterparts. The latest national data from the sector show that the gap between white students and BAME students obtaining first-class and 2:1 degrees is 15 percentage points (ECU 2017). DMU has a smaller, though still significant, difference of 10.7 percentage points. Historically, a deficit perspective has been used across the sector to counter this reality, rooted in the "view that the problem lies with the students and that it is some attribute of the student that means they attain less well, rather than because of an institutional factor such as curriculum design/development" (Miller, 2016).

This perspective offers no help addressing the attainment gap, as it shifts the focus away from what the institution can do - or, more importantly, should do - and places the onus on the student to provide a solution to problems that are grounded in social structures (Bhopal, 2018) or cultures of methodological whiteness (Bhambra, 2017). Analyses of structural racism inside the Academy have also framed work to decolonise and dismantle the curriculum and its organising principles, alongside the governance and management of universities (Ahmed, 2012; Arday and Mirza, 2018; Tuhiwai Smith et al., 2018). Elsewhere, more quantitative research has also demonstrated the problematic nature of this deficit perspective, as, even when a range of factors (including prior attainment) are controlled for, an unexplained difference still occurs between BAME and white students (Broecke and Nicholls, 2007; McDuff et al., 2018). 
This suggests that further exploration is needed to understand the lived experience of the curriculum for BAME students, who should increasingly shape the conversation if injustice is to be addressed. In this, there is potential for moving discussion of what 'success' means towards a broader understanding of the relationship the student has with themselves and the contexts in which they live and study, with their peers and with the institution. Thus, a greater focus has also been given to the 'softer' measures of success for student experience, "those related to a student's sense of personal accomplishment and satisfaction with the educational experience ... while such measures tend to be highly subjective, they can nonetheless be important to register for building up a holistic picture of success" (Singh, 2011, p.3). As more BAME students enter higher education (HE) it is crucial that university life is representative of all students, not just those from a hegemonic, white background. Greater cultural inclusivity in the curriculum is key to increasing students' sense of validity in their own lives and of being able to address societal issues, including critiques of belonging, as well as improved retention and attainment (NUS, 2011).

A crucial, pedagogic strand in this process of discovering what influences student success is supported at DMU through the use of co-creation between students and staff. Between January and April 2018, a series of pilot co-creation sessions brought together students and staff to discuss the attainment gap and how it might be positively addressed. The co-creation events were a valuable way not only to begin conversations with students, but also to review how the University communicates with its students and if current channels of communication are effectively reaching the groups with whom the project aims to work. This paper reflects on the approach taken to co-creation, the findings emerging from these initial discussions and the lessons learnt for future practice.

\section{The literature on co-creation}

Identified as one of three pillars of DMU's University Learning, Teaching and Assessment Strategy 2018-2023, co-creation is also a core tenet of the FTA project (DMU 2018). Through co-creation, student voices are acknowledged with the same credence given to those of academic and professional staff at the University, with their perspectives and experiences equally valued and respected. Partnership between students and staff helps to bridge the gap between these two communities and thereby support staff in understanding the student experience of campus life. It is particularly important where students and staff have different cultural backgrounds, as it presents new viewpoints for consideration. The hope is that this enables dominant viewpoints and modes of privilege to be challenged.

In relation to the wider context of the project, co-creation is a continuation of the critique of traditional education models with links to four key areas of pedagogic practice, namely:

- Friere's (1993) focus on critical, political pedagogy-as-praxis, through which indigenous communities govern, define and own the knowledge and process for challenging their marginalisation and oppression;

- Dewey's (1916) discussion of socially-democratic education, viewing the learner as the key contributor to epistemic development;

- bell hooks' (1994) critique of institutions which perpetuate existing hierarchies and thereby deny self-actualisation; 
- Giroux's (1983) critique of curriculum spaces as a preparation for students to challenge hegemony and to create a new society with their knowledge.

Co-creation also has links to established work on research-led and research-engaged teaching, through which the focus is on developing a curriculum that is extended through research, so that students learn through the process of investigation, evaluation and research (Burgum and Stoakes, 2016; Neary, 2010). In particular, this links the student experience with research that enables them to become engaged in the development of both their subject and their department / the University. Certainly, staff encouragement of students (at all levels and across all disciplines) to be active partners in - and producers of their learning (working with others and contributing to developments in their subjects) does challenge the idea that students are merely consumers or purchasers of educational services.

Such practices potentially destabilise the relationships between the student and themselves, the student and their peers and student and their institution, precisely because researchengaged teaching enables students to become active partners in the production of knowledge and meaning. If this is a re-imagining of the ways in which knowledge and practices are produced, then it challenges established positions and enables co-creation to challenge the methodological purity of institutions that reproduce attainment gaps between specific groups (Neary, 2016; Gabriel and Tate, 2017). However, it remains crucial that intersectional injustices are brought to the forefront during this process, so that other forms of marginalisation can be given voice - for instance, those which are related to class, gender, sexuality and ability (Joseph and Hirshfield, 2011; Steinpórsdóttir et al., 2017). This is a continuing process of dialogue rooted in a critique of pedagogic practice, which emerges through the process of co-creation.

However, this focus on pedagogy-as-praxis has been challenged by more recent drivers behind co-creation in HE, including the idea that the student is a consumer or purchaser of educational commodities. This idea of consumption tends to recalibrate pedagogic practice as an act of service, rather than one of partnership or cooperation in production (Healey et al., 2014). As Bovill (2013, p.100) argues, "there are differences between participating in University life, ensuring student voices are represented on university committees, and the idea of students becoming partners or co-creators of learning experiences". There are clear tensions between institutional governance and the organising principles for the curriculum, revealed in how they address co-creation and realised in terms of who has a voice and who is silenced.

The FTA project recognises these tensions and sees co-creation as crucial, both as a starting point for engaging with them and as a means of uncovering new relationships inside the institution that might serve as heuristics for analysing the attainment gap. Thus, three principles underpin co-creation as a process: respect; reciprocity and responsibility (CookSather et al. 2014). These are defined as follows.

- Respect - willingness to consider experiences that differ from our own; being open about the issue and open to the ideas of others. 
- Reciprocity - value of mutual exchange; sharing experiences and opinions; acknowledging that not everyone will contribute in the same ways, but that they will have equal opportunity to contribute.

- Responsibility - viewing the curriculum and the environment that is created on campus as the joint responsibility of students and staff.

What follows is an analysis of one institutional approach to the implementation of cocreation, in a way that recognises its own limitations in respect of the literature, but which also celebrates the possibilities of engaging in a developmental process at the level of the module, the programme and the institution.

\section{Approach to co-creation events}

An emergent, pilot phase of co-creation has enabled a scheme of programme-level sessions to be planned for the $2018 / 19$ academic year. In the pilot phase, a total of four co-creation events were held between January and April 2018. These consisted of two institution-wide events and two programme-level co-creation sessions, one in the Technology faculty and one in Health and Life Sciences; owing to the nature of the academic timetable in Arts, Design and Humanities and to a change in the FTA team within Business and Law, pilot events could not be held within these faculties. A total of sixty-five students participated in the events, accompanied by seventy members of staff, including ten members of the FTA team.

For the institution-wide events, emails were sent from a central University account to all staff and students and were backed up by central advertising and a project Twitter campaign. Programme leaders contacted students for the programme-level pilots. This approach was not successful in either case but provided the project team with a crucial learning moment which will be expanded upon later in this paper.

A critical role in this process is the Fair Outcomes Champion (FOC), working to enact change with curriculum teams and professional services staff. Six champions are currently in role at the University: four faculty-based champions, one Library and Learning Services' champion and one corporate champion. The Champion role is developmental and situates an understanding of the theoretical position against institutional data for attainment, mediated through an engagement with curriculum innovation. The focus is to help academics and professional services staff to understand and address the causes of inequitable outcomes for different groups of students. Within the context of co-creation, the FOCs facilitate the collaboration between student and staff groups, helping to initiate discussion and ensure reciprocity in the interaction. Moreover, the champions operate as a community of practice, meeting regularly to discuss limitations, barriers, challenges and successes in the development of empowering curriculum content, design, assessment and relationships.

To guide student and staff discussions about the attainment gap at the specific co-creation events, the FOCs reviewed the literature and devised four themes upon which to focus:

- Curriculum

- Environment 
- Development

- Community and belonging

Given that the aim of the co-creation events was to initiate an institution-wide conversation about the attainment gap and how it might be addressed, the four themes focus on the wider student experience and have been influenced by the work of Mountford-Zimdars et al. (2015), which identified the following factors which may explain difference in attainment:

- $\quad$ Curricula and learning - teaching and learning approaches, including assessment and feedback methods;

- $\quad$ Relationships between staff and students - developing a sense of belonging on campus, including that between student groups;

- $\quad$ Social, cultural and economic capital - how students draw on external support and how various student groups may have contrasting overall experience of $\mathrm{HE}$;

- $\quad$ Psychosocial and identity factors - how supported and encouraged students feel.

In order to evaluate the impact of these themes and factors on the experience of DMU students and staff, two forms of data were collected from attendees during the events: first, thoughts and suggestions on the attainment gap; second, feedback on the organisation and structure of the events themselves. In both cases, the data collected were qualitative. In both the institution-wide and programme-level events, stations were created for each theme, facilitated by a FOC. At each station, students and staff were encouraged to engage in conversation relating to the theme and capture their discussions by means of post-it notes. At the institution-wide events, post-it notes were collated on large theme boards whilst, at the later programme-level sessions, themes were split across four tables. To support the FOCs in their role as facilitators, a list of prompts for each theme was devised.

Given that post-it notes were written anonymously, the extent to which project team members were able to draw conclusions based on the voices represented by each theme was restricted. However, it is possible to infer from attendee sign-up sheets that the majority of participants were of a BAME background, which gives us a broad idea of the ethnic makeup of the voices represented. It is also important to consider that, without this anonymity, some participants might not have felt able to share their true thoughts, rooted in both structural and personal anxieties. The primary aim of these initial co-creation events was to initiate an institution-wide conversation; it was crucial then - and it continues to be essential - for us to do this in an open and honest way, in order to facilitate institutional change. Moreover, since such events act as an indicator of the institution's willingness to address injustice authentically, it was of fundamental importance to shape them as a safe space for dialogue.

Owing to time constraints, feedback for the institution-wide co-creation events was obtained from open comments left on postcards. The evaluation for the programme-level sessions, however, was more structured but retained open questions. In this case, the evaluation focused on: participants' experience of co-creation; what worked well in the session; what other questions could be asked; what improvements could be made; whether participants would be interested in co-creating in the future; and how understandings of the attainment gap had changed. 


\section{Data analysis}

Following each event, the post-it notes were transcribed and entered into computer-aided qualitative data analysis software (CAQDAS), organised by theme. A grounded theory approach was used to analyse the data, influenced by a critical race-theory lens. A critical race-grounded methodology allows for the exploration of data - without the influence of a hypothesis - to develop a theory with explanatory power rather than mere description. The guiding principle behind grounded theory is the notion that theory is emergent, rather than predefined, and through a critical race-theory lens, the approach helps to illuminate the experiences of those who are marginalised (Cohen et al., 2011; Malagon et al., 2009).

The analysis technique was influenced by Charmaz's (2014) coding methods and Alan Bryman's (2012) four-stage approach. These systems were combined, in order to create a structured process of analysis which best fits a grounded theory approach and which incorporates all three types of grounded-theory coding; open, axial and selective (Cohen et al., 2011).

- Get to know the data - Transcript is read and summarised, noting initial ideas.

- Initial coding - Text is broken up into units, compared and systematically coded, using an open-ended approach. As each new unit of data is coded, it is reviewed in comparison to the previous codes chosen to ensure that it is the most appropriate option.

- Focused coding - Codes and categories are reviewed in order to create links between them and to ensure best fit for the data. Codes and categories may be condensed at this stage.

- Reviewing themes - Themes are checked back against the dataset and a core code is identified, constituting "the foundations for any theory or general conclusions to emerge from the research" (Denscombe, 2014, p.288).

This process adopts the method of constant comparison, whereby new data is compared with existing data and categories to ensure the best possible fit. Given the range of data compared, this is often seen as consistent with the methodological notion of triangulation (Cohen et al., 2011). Cultural intuition can be utilised to support the research process, in line with a critical race-grounded methodology (Delgado Bernal, 1998; Malagon et al., 2009). A person's cultural intuition draws upon their personal experience, academic experience, professional experiences and the analysis process itself, acknowledging the role that the researcher plays in developing emerging theory from data - much like Charmaz's (2014) constructivist approach to grounded theory.

\section{Emergent themes}

A number of themes emerged from the institutional co-creation events and these were reinforced by the later findings of the programme-level co-creation. It is important to highlight, however, the difference - in prevalence in the themes - between the institutional events and the programme-level events, as shown in Table 1 below. It is likely that further variation will be found when the main phase of programme-level co-creation takes place from October 2018 and this may help to illuminate specific cultures associated with different disciplines. Owing to the anonymous nature of the events, it is not possible to identify the 
author of each statement made; however, the total number of references per topic is noted within the discussion below to give an indication of the prevalence of these subjects.

Table 1. Theme distribution

\begin{tabular}{|l|l|l|l|}
\hline Institution co-creation themes & Pilot programme co-creation themes \\
\hline Themes & References & Themes & References \\
\hline Relationships & 83 & Community & 44 \\
\hline Teaching and Learning & 36 & Relationships & 43 \\
\hline Development & 34 & Teaching and Learning & 37 \\
\hline Community & 24 & Development & 30 \\
\hline Exclusory Feelings & 7 & Employability & 28 \\
\hline & & Exclusory feelings & 4 \\
\hline
\end{tabular}

\section{Relationships}

The primary topics discussed within the theme of relationships were: role models (45), student integration (29), student-staff relationships (29), improved communication (17) and transparency of processes for dealing with issues of racism (6). There was a clear call for greater visibility of role models for BAME students, with such experience in and knowledge of their discipline to ensure relevance to these students' learning needs. This echoes wider national calls for greater diversity in academic staff, enabling students to see people like themselves within the institution and what their future could hold (Mountford-Zimdars et al., 2017).

"Bringing individuals from many different backgrounds who have completed their degree and are successful will encourage students in completing their degree and valuing their education."

It was highlighted that students tended to stick within their cultural groupings and that those students who lived at home and travelled in to study were most likely to feel isolated from their peers. Greater interaction between societies, use of social spaces across campus and introducing more events that encourage cultural integration were seen as potential methods for bringing students together and fostering a greater understanding between student groups.

"My idea is to not sit personal tutees/workshop groups based on surname as this restricts mixing with other ethnicities and backgrounds which hinders broadening horizons."

In support of this, improved communication about opportunities and events on campus was requested. It was noted that email was not always the most effective form of communication and that other approaches should be considered, but solutions were not specified. Whilst communication with programme teams was felt to be effective, cultural events were not always well publicised across the University, with often long invitation emails that some international students found difficult to decipher. 
Tutors' knowing the names of their students was seen as a simple way to make students feel recognised. Whilst students acknowledged that some staff made a clear effort to be available to their students through personal tutoring, it was also recommended that staff receive training to support them in understanding how they can support BAME students more effectively. HEFCE's (Stevenson, 2012) student retention and success programme found that both a sense of belonging and acknowledgment was crucial to both retention of and success for students. This is also an important thread of the Community theme within the data and will be discussed below.

Finally, it was felt that greater transparency in relation to the handling of race issues would improve BAME students' sense of security and would reassure them that, should an incident occur, it would be handled appropriately. In many ways, this is another facet of students' sense of belonging, feeling protected and having confidence that their wellbeing is prioritised by their institution.

\section{Teaching and Learning}

Student and staff discussions within this category focused primarily on: examples used in lectures (18), learning resources (9), student experience of learning (23) and lecturers' delivery methods and assessment styles (22). Of the highest priority to participants was the importance of BAME-inclusive examples and resources. Students requested more culturallydiverse, globalised curricula to increase the relevance to BAME students of content and to enhance their sense of belonging. This included more representative learning resources, to include a variety of voices and perspectives. The need to portray BAME individuals positively was also emphasised, with specific mention of the ways in which BAME communities are often negatively portrayed across curricula. Similar calls from the across the sector have highlighted the impact of perpetuating stereotypes through examples and case studies (NUS, 2011).

"I would like it if the curriculum included more inclusive, more positive stories/case studies/reinforcement for BAME students."

Learning materials were seen as easily accessible. However, delivery of the curriculum was identified as an area for improvement, with attendees requesting more engaging and inspiring delivery of curriculum content. There are connections here to a more relatable curriculum, as greater relevance will improve engagement for BAME students. At the institution-wide events, suggestions were made for assessment methods that allowed students to reflect on their cultural background and experience. At programme-level, students noted that assessments allowed them to incorporate their own skills and backgrounds and that feedback was effective in helping them to improve. This disparity could be because of the high representation of Business and Law students at the institutionwide events, whilst the programme-level events took place in Health and Life Sciences and Technology. The subjects taught within Business and Law traditionally have much larger cohorts of students, making it more challenging for staff to know each of their students on a personal level. 


\section{Community}

The notion of community included discussion of: co-creation (6), student societies (4), cultural inclusivity (12), campus development (9) and belonging (33). The concept of belonging was highlighted thirty-three times during the programme-level co-creation sessions, making it the most prominent individual code within those data. Interestingly, it was not explicitly raised at the institution-wide events; however, it has also been illustrated above that this concept is woven throughout all four of the themes emerging from the data. Within a critical race-grounded methodology, belonging is identified as the core code with the data. This will strongly influence the focus of continuing research upon digging deeper into the meaning of belonging with this institution.

"Personal experience is the environment is positive, welcoming and inclusive."

Attendees noted that they felt comfortable and safe at DMU, included in their courses and socially at ease with their course mates. Recent campus developments were also seen as a positive change, resulting in an increasingly welcoming environment. The many opportunities to engage with University life, such as volunteering and societies, had helped students to feel a part of the wider DMU community as well as within their courses. Where these feelings were not reflected, culturally-inclusive events were suggested as a method of improving all BAME students' sense of belonging across campus. Events that could bring students together to celebrate different cultural holidays and practices were seen as a positive way to increase student integration. Requests were also made for students' cultural practices to be considered in wider University planning - for example, contemplating the interaction between prayer times and lesson times. These simple actions could help to fulfil the University's responsibility for supporting student integration (Stevenson, 2012).

It was felt that further co-creation work could aid the University in addressing the attainment gap. This could include collaboration on displays in the library, providing input on their course (such as suggested readings), designing academic trips and explicitly working with staff on inclusivity. The events that have taken place to date and those planned for $2018 / 19$ are the beginning of a journey at DMU to embed co-creation into the heart of the University. Student societies were viewed as a potentially valuable resource for engaging with BAME students and it was felt during the co-creation pilot events that these were under-used.

\section{Development}

Discussions concerning development were focused on four key areas: access to support and development opportunities (20), development of academic skills (9), personal development (14) and support specifically for international students (6). Greater study support for BAME students was identified as needed, specifically with more one-to-one support for students regarding aspiration and wider personal development. Research has found that BAME students are less likely to come forward when in need of additional support and this is something which must be considered when advertising support opportunities (Miller 2016).

"We should try and create opportunities for ongoing professional development as a field in its own right as opposed to a tag on at the end of the degree." 
Students found support sessions run through the library very helpful, though some expressed concerns about gaining access to workshops and one-to-one sessions. It was also felt that tutors could support students by being aware of what help was available and signposting students to this. This would, of course, be predicated upon an effective relationship between students and tutors, for staff to know how best to direct their students to academic advice and guidance.

"DMU global has helped to reach my full potential, also being involved in volunteering - macMillan, square mile - boosted experience and employability."

Alongside academic development, the value of extra-curricular experiences was also noted. DMU Global, the University's international experience programme, and DMU Local, the university's community engagement programme, were seen as valuable opportunities to broaden student horizons and encourage personal development.

"Offer cultural difference curriculum for international students."

It was felt that BAME students would benefit from support in raising academic confidence and ambition. Related to this was the specific request for increased support for international students. Statements suggested that international students experienced a significant culture shock when arriving at the University, not only in terms of their interactions on campus but also in relation to the organisation of their study.

\section{Employability}

Students and staff highlighted three main topics under the theme of employability: practical experience (12), specialised careers advice (11) and placements (7). It is important to note that, as the majority of students participating in the programme-level sessions were in their final year of undergraduate study, this may have skewed the focus of discussions. However, during the institutional co-creation sessions, nearly half of all development statements forty-seven per cent - referred directly to employability and placements, suggesting that this is an important area of work across campus.

"Placements and experience to help enhance our careers in the future."

It was explicitly noted that, whilst BAME students were aware of employability support across the University, they did not feel that they were able to access it as easily as their white peers. Reasons for this were not given. The value of placements was also recognised, though BAME students also felt they had reduced access to these opportunities. There may be links here to the Relationships category and issues concerning communication with students. Particularly, it may be useful to consider how BAME students interact most frequently with information at University, to ensure that those channels are effectively utilised.

"Being clear on where the degree can lead to, it isn't clear where I can fit in with this degree, the personal and academic development has been good but where to go after is still a blur." 
Students identified a need for more opportunities to gain practical experience and develop the practical skills they would need to succeed in their careers. It was also highlighted that, though the programme had a very broad range of applicability, students were not clear about what they could do with their degree after graduation. This was in relation to both career choices and further study.

Students believed that greater involvement of alumni could help to alleviate this concern. By inviting past students back to the University to share their post-graduation journey, current students would be given a clearer idea of what they might do with their qualification. Placements were also mentioned throughout the session and suggestions were made regarding the use of enhancements weeks to allow short-term work placement.

\section{Exclusion}

"I feel most comfortable at home in my flat. I used to feel comfortable in my safe spaces like prayer rooms but due to higher surveillance I am prevented. And I know students don't feel comfortable talking about such issues."

Whilst only three per cent of statements related to students' feeling excluded at University, these experiences are crucial to highlight so that the reasons behind them can be explored. Particularly in the light of the prevalence of belonging as a key concept within the data, understanding student experiences where the opposite outcome has occurred is vital. Here, the project potentially reflects the literature on dismantling and decolonising race in the Academy, where it enables the socio-cultural power of whiteness and established privilege to be further challenged (Arday and Mirza, 2018). Attendees noted a feeling of not belonging at University, owing to the inherent white culture present in many UK HE institutions. There was also a feeling that much of the representation of BAME communities within their curricula was negative, as noted within the Teaching and Learning category, perpetuating this feeling that they do not belong.

\section{Lessons for future practice}

To inform future co-creation sessions, feedback was gathered at both the institutional and programme-level events. Feedback was predominantly positive and constructive, helping the FTA team to consider how the sessions can continue to be improved. Overall, participants were pleased and reassured to see that DMU is working openly on the attainment gap and that student voice is a valued aspect of this work. Students felt that their opinions were heard and that DMU was attempting to affect real change through the FTA project. Working in small groups with their peers, in an environment where they were encouraged to speak openly, was seen as a strength of the co-creation approach. Question prompts for each of the four themes were also seen as a helpful and stimulating resource.

"Everyone got to speak freely, led by people who want to listen and make a difference."

Staff found the insights from students very interesting and considered the overall experience of working in this way with their students positive. They were grateful to see that students were honest and open about their experiences of studying on their programme and considered that a number of manageable changes that had been identified could improve student experience. They felt that the willingness of students to talk freely was a particular 
strength of the session, but that staff positionality within that space could have been discussed further. Staff also felt that greater representation of the diversity of their students would improve the session.

Staff were also keen to continue to engage with co-creation activities and felt that the experience had strengthened their desire to work towards making positives changes at DMU. Students stated that they would be happy to engage with co-creation activities again in the future. They noted that the session had changed their understanding of DMU's position on the attainment gap and were now more aware of the work that DMU is undertaking and the importance that the attainment gap has at DMU. This is an important marker, in terms of who has a voice in defining the curriculum and access to it.

The events provided an opportunity to learn valuable lessons about the situations that encouraged participation. In particular, they highlighted issues concerning the effectiveness of the institution's communication with students, as many had never heard of the project or associated events before. Students felt that greater awareness of the events would have improved student attendance and therefore increased the representation of student voice at the events. As part of the wider FTA project plan, a group of Student Curriculum Advisers (SCAs) will be joining the team in the $2018 / 19$ academic year. Their primary role will be to engage with students across the project, and more widely across the University, to share their thoughts and insights into the needs of BAME students and consider how these views can be relayed to lecturers and wider University staff to support changes in practice. In addition to this, the FTA team will utilise the experiences and knowledge of the SCAs to consider a more effective communication strategy.

Based on the findings, feedback and reflections of the FTA team on the sessions held, recommendations were generated for the main phase of programme-level co-creation events, in relation to their design, organisation and promotion. These recommendations focused upon four key tenets:

1. Staff development - staff development around co-creation would be beneficial for staff to engage confidently and productively in the co-creation process. This links to wider work across the institution which aims to "facilitate the dynamic co-creation of learning opportunities and development of academic disciplines" (DMU, 2018). In this way, FTA will model best practice for the wider institution.

2. Project visibility - in order to promote the project and give students a better idea of what the sessions will involve, FOCs should be invited to attend the beginning of a lecture for each programme, to introduce in person the project and co-creation events. The appointment of Student Curriculum Advisors will also create opportunities to work with students to devise more effective methods of communication with the student body.

3. Project transparency - the introductory segment of the co-creation events must be upfront, honest and transparent to encourage students and staff to share their experiences and ideas in a similarly open way. It should also outline how the data collected during the session will be used in support of FTA to ensure that students and staff understand the value of their participation.

4. Project flexibility - following the pilot events, the content of the co-creation schedule has been reviewed to focus on the key themes identified in the institutional and pilot 
sessions. It is important to consider, however, how specific themes used within each of the co-creation sessions may need to be locally negotiated with programme teams to ensure relevance and full potential benefit.

Crucially, these recommendations stitch into the underpinning principles of co-creation, namely respect, reciprocity and responsibility. These operate at the level of the individual, the programme and the institution, in order that the deep structural injustices in relation to the attainment gap may be acknowledged. In the process of acknowledgement, the FTA team is using the project as a moment for deeper reflexivity in challenging privilege and opening out the institution to a more authentic set of relationships.

\section{Reference list}

Ahmed, S. (2012) On Being Included: Racism and Diversity in Institutional Life. Durham, NC: Duke University Press.

Arday, J. and Mirza, H.S. (2018) Dismantling Race in Higher Education: Racism, Whiteness and Decolonising the Academy. London: Palgrave Macmillan.

Bhambra, G. (2017) 'Brexit, Trump, and methodological whiteness: on the misrecognition of race and class.' The British Journal of Sociology. 68(1), 214-32.

Bhopal, K. (2018) White Privilege: the myth of a post-racial society. Bristol: Policy Press.

Bovill, C. (2013) 'Students and staff co-creating curricula: a new trend or an old idea we never got around to implementing?' In: Rust, C. (ed.) Improving Student Learning Through Research and Scholarship: 20 Years of ISL. Series: Improving student learning (20). Oxford Centre for Staff and Learning Development: Oxford, UK, 96-108.

Broecke, S. and Nicholls, T. (2007) Ethnicity and Degree Attainment. DfES Research Report RW92. London: DfES.

Bryman, A. (2012) Social Research Methods. Oxford: Oxford University Press.

Burgum, S. and Stoakes, G. (2016) What does research informed teaching look like? The Higher Education Academy/University alliance. Available at: http://bit.ly/2h2JLke (Accessed: 20 August 2018).

Charmaz, K. (2014) Constructing Grounded Theory. Second edition. London: Sage.

Cohen, L., Manion, L. and Morrison, K. (2011) Research Methods in Education. London: Routledge.

Cook-Sather, A., Bovill, C. and Felten, P. (2014) Engaging students as partners in learning and teaching: a guide for faculty. San Francisco: Jossey-Bass. 
De Montfort University (2018) University Learning, Teaching and Assessment Strategy 2018 - 2023: Providing a Transformative and Co-Created Education and Student Experience.

Leicester: DMU.

Delgado Bernal, D. (1998) 'Using a Chicana Feminist Epistemology in Educational Research.' Harvard Educational Review, 68(4).

Denscombe, M. (2014) The Good Research Guide: for small-scale social research projects. Maidenhead: McGraw-Hill Education.

Dewey, J. (1916) Democracy and education: an introduction to the philosophy of education. New York: The Macmillan Company.

ECU (2017) Equality in higher education: statistical report 2017.

Freire, P. (1993) Pedagogy of the oppressed. Revised ed. London: Penguin.

Gabriel, D. and Tate, S.A. (2017) Inside the Ivory Tower: Narratives of women of colour surviving and thriving in British academia. Stoke-on-Trent: Trentham Books.

Giroux, H.A. (1983) Theory and resistance in education. A pedagogy for the opposition. London: Heinemann.

Healey, M., Flint, A. and Harrington, K. (2014) Engagement through partnership: students as partners in learning and teaching in higher education. The Higher Education Academy.

Available at: http://bit.ly/2s5UYbF (Accessed 20 August 2018)

Hooks, B. (1994) Teaching to Transgress: Education as the Practice of Freedom. London: Routledge.

Tiffany, J. and Hirshfield, L. (2011) 'Why don't you get somebody new to do it? Race and cultural taxation in the academy.' Ethnic and Racial Studies 34(1): 121-41.

Malagon, M.C., Perez Huber, L. and Velez, V.N. (2009) 'Our Experiences, Our Methods: Using Grounded Theory to inform a Critical Race Theory Methodology.' Seattle Journal for Social Justice, 8 (1), 253-272.

McDuff, N., Tatam, J., Beacock, O. and Ross, F. (2018) 'Closing the attainment gap for students from black and minority ethnic backgrounds through institutional change.' Widening Participation and Lifelong Learning, 20(1), 79-101.

Miller, M. (2016) The Ethnicity Attainment Gap: literature review. Sheffield: The University of Sheffield Widening Participation Research \& Evaluation Unit.

Mountford-Zimdars, A., Sabri, D., Moore, J., Sanders, J., Jones, S. and Higham, L. (2015) Causes of differences in student outcomes. Location: HEFCE.

Mountford-Zimdars, A., Sanders, J., Moore, J., Sabri, D., Jones, S. and Higham, L. (2017) 'What can universities do to support all their students to progress successfully throughout 
their time at university?' Perspectives: Policy and Practice in Higher Education, 21(2-3), 101110.

National Union of Students (2011) Liberation, Equality, and Diversity in the Curriculum.

Neary, M. (2010) Student as producer: a pedagogy for the avant-garde? Learning Exchange, $1(1), 2$.

Neary, M. (2016) 'Student as Producer: The Struggle for the Idea of the University.' Other Education: The Journal of Educational Alternatives, 5(1), 90.

Singh, G. (2011) Black and minority ethnic (BME) students' participation in higher education: improving retention and success. A synthesis of research evidence. Coventry: HEA.

Steinpórsdóttir, F.S., Heijstra, T.M. and Einarsdóttir, P.J. (2017) 'The making of the excellent university: A drawback for gender equality.' ephemera: theory and politics in organization, 17(3), 557-82.

Stevenson, J. (2012) Black and minority ethnic student degree retention and attainment. York: HEA.

Tuhiwai Smith, L., Tuck, E. and Yang, K.W. (eds.) (2018) Indigenous and Decolonizing Studies in Education: Mapping the Long View. Introduction. London: Routledge, 1-23. 